\title{
Evaluation of adrenal function in patients with growth hormone deficiency and hypothalamic-pituitary disorders: comparison between insulin-induced hypoglycemia, low-dose ACTH, standard ACTH and CRH stimulation tests
}

\author{
M Maghnie, E Uga, F Temporini, N Di Iorgi, A Secco, C Tinelli ${ }^{1}$, A Papalia ${ }^{2}$, MR Casini ${ }^{3}$ and S Loche $^{3}$ \\ Department of Pediatrics, ${ }^{1}$ Department of Biometry - Scientific Direction, ${ }^{2}$ Servizio Analisi Chimico Cliniche, IRCCS Policlinico S. Matteo, \\ University of Pavia, I-27100 Pavia, Italy and ${ }^{3}$ Pediatric Endocrine Service, Ospedale Regionale le Microcitemie, Cagliari, Italy \\ (Correspondence should be addressed to M Maghnie; Email: maghnie@smatteo.pv.it)
}

\begin{abstract}
Objectives: Patients with organic growth hormone deficiency (GHD) or with structural hypothalamicpituitary abnormalities may have additional anterior pituitary hormone deficits, and are at risk of developing complete or partial corticotropin (ACTH) deficiency. Evaluation of the integrity of the hypothalamic-pituitary-adrenal axis (HPA) is essential in these patients because, although clinically asymptomatic, their HPA cannot appropriately react to stressful stimuli with potentially life-threatening consequences.

Design and methods: In this study we evaluated the integrity of the HPA in 24 patients (age 4.2-31 years at the time of the study) with an established diagnosis of GHD and compared the reliability of the insulin tolerance test (ITT), short synacthen test (SST), low-dose SST (LDSST), and corticotropin releasing hormone (CRH) test in the diagnosis of adrenal insufficiency.

Results: At a cortisol cut-off for a normal response of $550 \mathrm{nmol} / \mathrm{l}(20 \mu \mathrm{g} / \mathrm{dl})$, the response to ITT was subnormal in 11 subjects, 6 with congenital and 5 with acquired GHD. Four patients had overt adrenal insufficiency, with morning cortisol concentrations ranging between $66.2-135.2 \mathrm{nmol} / \mathrm{l}(2.4-$ $4.9 \mu \mathrm{g} / \mathrm{dl}$ ) and typical clinical symptoms and laboratory findings. In all these patients, a subnormal cortisol response to ITT was confirmed by LDSST and by CRH tests. SST failed to identify one of the patients as adrenal insufficient. In the seven asymptomatic patients with a subnormal cortisol response to ITT, the diagnosis of adrenal insufficiency was confirmed in one by LDSST, in none by SST, and in five by CRH tests. The five patients with a normal cortisol response to ITT exhibited a normal response also after LDSST and SST. Only two of them had a normal response after a CRH test. In the seven patients with asymptomatic adrenal insufficiency mean morning cortisol concentration was significantly higher than in the patients with overt adrenal insufficiency. ITT was contraindicated in eight patients, and none of them had clinical symptoms of overt adrenal insufficiency. One of these patients had a subnormal cortisol response to LDSST, SST, and CRH, and three exhibited a subnormal response to CRH but normal responses to LDSST and to SST.

Conclusion: We conclude that none of these tests can be considered completely reliable for establishing or excluding the presence of secondary or tertiary adrenal insufficiency. Consequently, clinical judgment remains one of the most important issues for deciding which patients need assessment or re-assessment of adrenal function.
\end{abstract}

European Journal of Endocrinology 152 735-741

\section{Introduction}

A substantial number of patients with isolated growth hormone deficiency (GHD) may have additional anterior pituitary hormone deficits $(1-3)$. Patients with idiopathic GHD are at risk of developing complete or partial corticotropin (ACTH) deficiency. Lange et al. (4) have recently reported that $44 \%$ of adult subjects with childhood-onset GHD developed asymptomatic adrenal insufficiency. Walvoord et al. reported that all but one patient with GHD and additional ACTH deficiency had an ectopic posterior pituitary at magnetic resonance imaging (5). However, although clinically asymptomatic, the hypothalamic-pituitaryadrenal axis (HPA) of these patients cannot appropriately react to stressful stimuli, with potentially lifethreatening consequences. Thus, evaluation of the integrity of the HPA is essential in patients with GHD. 
Although the diagnosis of overt adrenal failure is generally straightforward, identification of those asymptomatic patients with subtle dysfunction of the HPA axis is still a diagnostic challenge. The HPA axis response to insulin hypoglycemia (ITT) is still considered the gold standard in the evaluation of suspected adrenal insufficiency, even though its validity has been recently questioned (6-8). Furthermore, ITT is contraindicated in infants, and in patients with cardiovascular disease or a history of seizures. Patients with multiple pituitary hormone deficiencies experienced severe hypoglycemia during ITT (9), and occasional deaths in children have been reported with the use of such tests (10). Therefore, alternative tests to evaluate the HPA have been proposed, such as glucagone, metyrapone, ACTH and corticotropin releasing hormone $(\mathrm{CRH})$ testing $(4,6)$. Since the adrenal gland can respond to exogenous ACTH administration when there is a sufficient endogenous ACTH reserve, the short synacthen test (SST) has been introduced to test the HPA in patients with secondary adrenal insufficiency or after corticosteroid withdrawal (11). More recently, a low-dose $(1 \mu \mathrm{g})$ SST (LDSST) has been proposed to be more sensitive in the evaluation of the integrity of the HPA (12-17). Results of CRH testing have been reported in some patients with adrenal insufficiency $(18-20)$, and a good correlation was found between the responses to CRH and ITT.

This study was prospectively designed to test the integrity of the HPA axis in patients with an established diagnosis of GHD. Since ITT was contraindicated in many of our patients, we designed this study to compare the reliability of the ITT, SST, LDSST and CRH test in the diagnosis of adrenal insufficiency.

\section{Subjects and methods}

The study population comprised 24 patients (12 males and 12 females) with established childhood-onset GHD of congenital or acquired origin, diagnosed at a mean age of 9.6 \pm 6.0 years (range 2.0-20.0 years). The diagnosis of GHD was established on the basis of failure of growth hormone (GH) to increase $>10 \mu \mathrm{g} / \mathrm{l}$ after two stimulation tests (insulin hypoglycaemia and arginine). In all patients, insulin-like growth factor-I (IGF-I) concentrations were lower than those of age-matched normal subjects. Nine patients had vasopressin deficiency, two had thyrotropin (TSH) deficiency (one after cranial irradiation), five had gonadotropin deficiency and one had hypergonadotropic hypogonadism (chemotherapy-induced). All patients were receiving appropriate hormonal replacement treatment for their hormonal deficits. Subjects with multiple pituitary hormone deficiencies (MPHD) were receiving conventional replacement therapy for pituitary deficits: L-thyroxine (150 $\mu \mathrm{g}$ per day), hydrocortisone (20-25 mg per day in two to three separate doses), testosterone enanthate
(150-250 mg intramuscularly every 2 or 3 weeks for males and transdermal $17 \beta$-estradiol patches with medroxyprogesterone acetate $(5-10 \mathrm{mg}$, days 12 to 21) for females), desmopressin acetate (DDAVP; two or three times daily, either intranasally or orally in cases with central diabetes insipidus) and recombinant human GH $(0.025-0.030 \mathrm{mg} / \mathrm{kg} /$ week, given s.c. 6 to 7 times/week to pediatric-age patients and at a dose of between $0.5-1 \mathrm{mg} /$ day to the others).

Magnetic resonance imaging (MRI) technique with the use of contrast medium as previously described (21) revealed congenital hypothalamic-pituitary abnormalities, such as anterior pituitary gland hypoplasia, pituitary stalk agenesis and posterior pituitary ectopia at the infundibular recess $(n=12)$ and acquired lesions, including idiopathic, likely 'inflammatory', pituitary stalk thickness $(n=5)$, Langherans cells histiocytosis (LCH)-dependent pituitary stalk thickness $(n=4)$, brain tumor $(n=1)$, pituitary hypoplasia as the result of head trauma and skull fracture $(n=1)$ and pituitary adenoma $(n=1)$. The diagnosis of idiopathic pituitary stalk thickness was based on MR findings of a large pituitary stalk (22) in the absence of other imaging or laboratory markers of specific diseases, including LCH, sarcoidosis, tuberculosis, germinomas or systemic disorders. Biopsy-proven LCH at the level of skin or bone lesions were obtained in all affected patients.

The main clinical findings of the patients are summarized in Table 1 . The study was approved by the Department of Pediatrics Institutional Review Board and written informed consent was obtained from the patients and their patients.

\section{Study design}

The ITT (0.1 U/kg BW i.v. of human Actrapid insulin) was performed in 16 patients, since it was contraindicated in eight subjects. Plasma cortisol and glucose were measured at baseline and at time points 30, 60, 90 , and $120 \mathrm{~min}$ after insulin administration. Results were accepted if blood glucose had dropped to levels below $2.2 \mathrm{nmol} / \mathrm{l}(<40 \mathrm{mg} / \mathrm{dl})$ in association with glucopenic symptoms. Blood samples for cortisol and plasma glucose were drawn from an indwelling catheter inserted in an antecubital vein and measured at baseline and at time points $30,60,90$, and $120 \mathrm{~min}$ after insulin administration.

The LDSST was performed in all patients. Blood samples for cortisol were measured at time points 0 , $10,20,30$ and $45 \mathrm{~min}$ after the injection of $1 \mu \mathrm{g}$ tetracosactrin (Synacthen, Novartis Pharma S.A., Huningue, France). A dilute solution was prepared by adding $250 \mu \mathrm{g}$ to $50 \mathrm{ml} 0.9 \% \mathrm{NaCl}$ in a plastic infusion bag. Further dilution was performed by taking $0.2 \mathrm{ml}$ of the solution and adding $0.8 \mathrm{ml} \mathrm{NaCl}$. The resulting solution of $1 \mu \mathrm{g} \mathrm{ACTH} / \mathrm{ml}$ was used immediately after preparation. 
Table 1 Characteristics of 24 patients with GH deficiency of different etiology.

\begin{tabular}{|c|c|c|c|c|c|}
\hline Patient & Sex & Age/diagnosis (years) & Age/study (years) & Etiology & Hormone deficits \\
\hline 1 & M & 4.2 & 4.2 & EPP, APH, PSA & $\mathrm{GH}$ \\
\hline 2 & $\mathrm{~F}$ & 3.2 & 10.8 & EPP, APH, PSA & $\mathrm{GH} / \mathrm{FSH} / \mathrm{LH}$ \\
\hline 3 & $\mathrm{~F}$ & 2.0 & 16.6 & EPP, APH, PSA & $\mathrm{GH} / \mathrm{FSH} / \mathrm{LH}$ \\
\hline 4 & $\mathrm{~F}$ & 6.4 & 17.2 & EPP, APH, PSA & $\mathrm{GH}$ \\
\hline 5 & $M$ & 8.5 & 17.6 & EPP, APH, PSA & $\mathrm{GH}$ \\
\hline 6 & $\mathrm{M}$ & 2.0 & 17.6 & EPP, APH, PSA & $\mathrm{GH} / \mathrm{FSH} / \mathrm{LH}$ \\
\hline 7 & $\mathrm{~F}$ & 14.0 & 21.2 & EPP, APH, PSA & $\mathrm{GH} / \mathrm{FSH} / \mathrm{LH}$ \\
\hline 8 & $\mathrm{~F}$ & 6.6 & 21.9 & EPP, APH, PSA & $\mathrm{GH}$ \\
\hline 9 & $\mathrm{M}$ & 4.0 & 22.2 & EPP, APH, PSA & $\mathrm{GH} / \mathrm{FSH} / \mathrm{LH}$ \\
\hline 10 & $M$ & 9.0 & 24.1 & EPP, APH, PSA & $\mathrm{GH}$ \\
\hline 11 & $\mathrm{~F}$ & 11.6 & 31.0 & EPP, APH, PSA & $\mathrm{GH} / \mathrm{FSH} / \mathrm{LH}$ \\
\hline 12 & $M$ & 8.7 & 13.7 & IPST & GH/AVP \\
\hline 13 & $\mathrm{M}$ & 13.2 & 13.9 & IPST & $\mathrm{GH} / \mathrm{FSH} / \mathrm{LH} / \mathrm{AVP}$ \\
\hline 14 & $\mathrm{M}$ & 6.3 & 14.8 & IPST & GH/AVP \\
\hline 15 & $\mathrm{M}$ & 12.8 & 16.8 & IPST & GH/AVP \\
\hline 16 & $\mathrm{M}$ & 9.8 & 17.0 & IPST & GH/AVP \\
\hline 17 & $\mathrm{~F}$ & 9.7 & 18.3 & IPST & $\mathrm{GH} / \mathrm{FSH} / \mathrm{LH} / \mathrm{AVP}$ \\
\hline 18 & $\mathrm{~F}$ & 11.0 & 11.6 & $\mathrm{LCH}$ & GH \\
\hline 19 & $\mathrm{~F}$ & 9.5 & 16.9 & $\mathrm{LCH}$ & GH/AVP/hypogonadism ${ }^{a}$ \\
\hline 20 & $\mathrm{M}$ & 20.0 & 25.8 & $\mathrm{LCH}$ & GH/AVP/TSH \\
\hline 21 & $\mathrm{M}$ & 8.2 & 25.8 & $\mathrm{LCH}$ & GH/FSH/LH/AVP \\
\hline 22 & $\mathrm{~F}$ & 5.6 & 15.6 & brain tumor & $\mathrm{GH} /$ hypothyroidism $^{\mathrm{b}}$ \\
\hline 23 & $\mathrm{~F}$ & 18.0 & 18.3 & head trauma & GH/FSH/LH \\
\hline 24 & $\mathrm{~F}$ & 18.2 & 21.5 & adenoma & $\mathrm{GH} / \mathrm{FSH} / \mathrm{LH}$ \\
\hline
\end{tabular}

EPP, ectopic posterior pituitary; APH, anterior pituitary hypoplasia; PSA, pituitary stalk agenesis; IPST, idiopathic pituitary stalk thickness; LCH, Langerhans-cell hystiocytosis; adenoma, pituitary non-secreting adenoma.

a Hypergonadotropic hypogonadism.

${ }^{\mathrm{b}}$ Acquired hypothyroidism.

The SST ( $250 \mu \mathrm{g}$ tetracosactrin; Synacthen) and the CRH tests $(1 \mu \mathrm{g} / \mathrm{kg}$ human CRH, Ferring Arzneimittel $\mathrm{GmbH}$, Wittland, Kiel, Germany) were performed i.v. in all patients. Blood samples for cortisol were taken at time points 0,30 , and 60 min after both tests.

All tests were performed in the morning between 0800-0900 h after the patients had fasted overnight. The 4 tests were performed within 1 month on separate days after an interval of 7 days. The samples were centrifuged at $4{ }^{\circ} \mathrm{C}$, and the plasma was separated and stored at $-20^{\circ} \mathrm{C}$ until assayed. A serum cortisol increase to at least $550 \mathrm{nmol} / \mathrm{l}(20 \mu \mathrm{g} / \mathrm{dl})$ was the criterion for a functioning HPA (provided the blood glucose nadir was $2.2 \mathrm{nmol} / \mathrm{l}$ or $<40 \mathrm{mg} / \mathrm{dl}$ during ITT).

In our laboratory, normal morning cortisol concentrations are $138-635 \mathrm{nmol} / \mathrm{l}(5-23 \mu \mathrm{g} / \mathrm{dl})$, while the cut-off for a normal cortisol response is $>550 \mathrm{nmol} / \mathrm{l}$ $(20 \mu \mathrm{g} / \mathrm{dl})$ to ITT, SST, and LDSST and $>500 \mathrm{nmol} / \mathrm{l}$ $(18 \mu \mathrm{g} / \mathrm{dl})$ to $\mathrm{CRH}$. These cut-off points have been established in 43 normal subjects after ITT, 28 after SST, 25 after LDSST and 20 after CRH. Data are given as the mean \pm S.E.

\section{Assay procedures}

Cortisol was measured by radioimmunoassay using commercial kits (Elecsys, Roche Diagnostics, Mannheim, Germany). The intra- and inter-assay coefficients of variations were $1.3,1.3$ and $1.1 \%$, and 1.6 ,
1.5 and $1.6 \%$, respectively at cortisols level of 207.8 , 560.0 and $1269.1 \mathrm{nmol} / \mathrm{l}(7.53,20.3$ and $46 \mu \mathrm{g} / \mathrm{dl})$. Serum glucose was routinely determined with the glucose oxidase method.

\section{Results}

All 16 patients who underwent the ITT had dropped blood glucose to levels below $2.2 \mathrm{nmol} / \mathrm{l}(<40 \mathrm{mg} / \mathrm{dl})$ and exhibited one or more clinical symptoms and signs of hypoglycemia, including tachycardia, a sense of hunger, sweating or mental confusion. With a cutoff for a normal response of $550 \mathrm{nmol} / \mathrm{l}(20 \mu \mathrm{g} / \mathrm{dl})$, the cortisol peak after ITT was subnormal in 11 subjects, six with congenital and five with acquired GHD (Fig. 1). Four patients (patients 7, 12, 13 and 15) had overt adrenal insufficiency, with morning cortisol concentrations ranging between $66.2-135.2 \mathrm{nmol} / \mathrm{l}$ $(2.4-4.9 \mu \mathrm{g} / \mathrm{dl})$ and typical clinical symptoms and laboratory findings (Table 2). In all these patients, a subnormal cortisol response to ITT was confirmed by LDSST and by CRH test. SST failed to identify one of the patients as adrenal insufficient (Fig. 1). In the seven asymptomatic patients with a subnormal cortisol response to ITT (patients 1, 3, 6, 10, 11, 14 and 16), the diagnosis of adrenal insufficiency was confirmed in one (patient 6) by LDSST, in none by SST, and in five patients (patients 1, 3, 6, 14 and 16) by CRH 


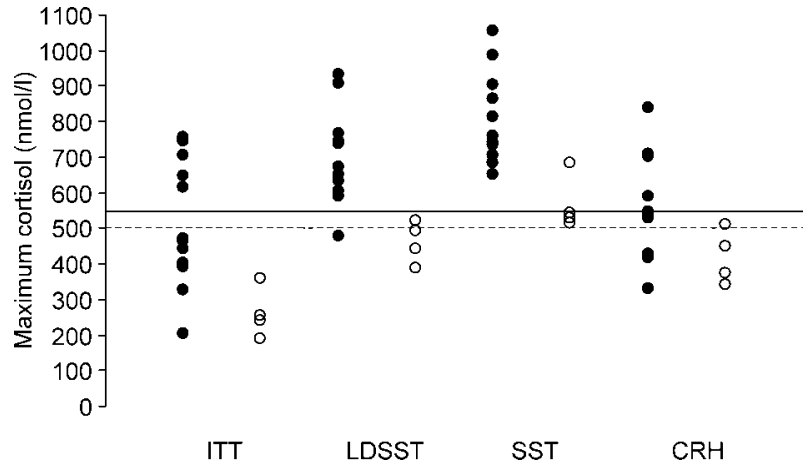

Figure 1 Comparisons between the maximum cortisol responses of four affected patients with overt adrenal insufficiency (o) and the remaining 12 patients $(\bullet)$ after insulin-induced hypoglycemia (ITT), low-dose short synacthen test (LDSST), short synacthen test (SST) and $\mathrm{CRH}$ test.

(Fig. 1). The five patients with a normal cortisol response to ITT (patients 2, 9, 17, 18 and 21) exhibited a normal response also after LDSST and SST. Only two of them had a normal response after $\mathrm{CRH}$ (patients 9 and 18) (Fig. 1). Mean baseline cortisol concentrations were significantly lower in the four patients with overt adrenal insufficiency than in the five patients with a normal response to ITT $(P=0.03$ by Mann-Whitney $\mathrm{U}$ test). In the seven patients with asymptomatic adrenal insufficiency, mean morning cortisol concentration was significantly higher than in the patients with overt adrenal insufficiency $(234.5 \pm 35.9$ vs $104.8 \pm 33.1 \mathrm{nmol} / \mathrm{l}(8.5 \pm 1.3$ vs. $3.8 \pm 1.2 \mu \mathrm{g} / \mathrm{dl})$ $P=0.0001$ by Mann-Whitney $U$ test). None of the patients in whom ITT was contraindicated (patients $4,5,8,19,20,22,23$ and 24) had clinical symptoms of overt adrenal insufficiency. One of these patients (patient 5) had a subnormal cortisol response to LDSST, SST, and CRH. Three more patients (patients $8,22,24)$ exhibited a subnormal response to $\mathrm{CRH}$ but normal responses to LDSST and to SST (Fig. 2).

\section{Discussion}

The clinical spectrum of adrenal insufficiency ranges from the clinically manifest adrenal crisis to subtle dysfunctions in asymptomatic patients. Patients with slight dysfunctions are at risk of developing acute adrenal crisis since their HPA cannot appropriately react to stress. Thus, identification of patients with subtle abnormality of the HPA is mandatory for avoiding this life-threatening event in stressful conditions. Patients with GHD are particularly at risk of developing adrenal insufficiency (1-4), and those with multiple pituitary hormone deficiency may have a lower secretory cortisol capacity than healthy subjects (23), suggesting that careful monitoring of HPA in these patients is recommended. The cortisol

Table 2 Morning cortisol and clinical manifestations of patients with GH deficiency who underwent dynamic adrenal testing.

\begin{tabular}{|c|c|c|c|c|c|c|}
\hline Patient & $\begin{array}{c}\text { Morning cortisol } \\
\mathrm{nmol} / / \mathrm{l}(\mu \mathrm{g} / \mathrm{dl})\end{array}$ & Fatigue & $\begin{array}{c}\text { Orthostatic } \\
\text { hypotension }\end{array}$ & $\begin{array}{l}\text { Gastrointestinal } \\
\text { symptoms }\end{array}$ & Pallor & $\begin{array}{c}\text { Depression } \\
\text { anorexia }\end{array}$ \\
\hline $1^{a}$ & $215.2(7.8)$ & + & - & - & - & - \\
\hline $2^{b}$ & $251.1(9.1)$ & - & - & _- & - & _- \\
\hline $3^{a}$ & $179.3(6.5)$ & + & - & - & - & - \\
\hline 4 & $350.4(12.7)$ & + & - & - & - & - \\
\hline 5 & $240.0(8.7)$ & + & - & + & - & - \\
\hline $6^{a}$ & $245.6(8.9)$ & + & - & - & - & - \\
\hline $7^{\mathrm{c}}$ & 135.2 (4.9) & + & - & + & + & + \\
\hline 8 & $270.4(9.8)$ & + & + & - & - & - \\
\hline $9^{b}$ & 240.0 (8.7) & - & - & - & - & - \\
\hline $10^{\mathrm{a}}$ & $212.4(7.7)$ & - & - & - & - & - \\
\hline $11^{a}$ & $259.3(9.4)$ & + & - & - & - & - \\
\hline $12^{\mathrm{c}}$ & $129.7(4.7)$ & + & + & - & + & - \\
\hline $13^{c}$ & $93.8(3.4)$ & + & + & - & + & - \\
\hline $14^{\mathrm{a}}$ & $284.2(10.3)$ & - & - & - & - & - \\
\hline $15^{\mathrm{c}}$ & $66.2(2.4)$ & + & + & + & - & - \\
\hline $16^{a}$ & $248.3(9.0)$ & + & - & - & _- & _- \\
\hline $17^{\mathrm{b}}$ & $237.3(8.6)$ & - & - & - & - & - \\
\hline $18^{\mathrm{b}}$ & $226.2(8.2)$ & - & - & - & - & - \\
\hline 19 & 300.7 (10.9) & - & - & - & - & - \\
\hline 20 & $435.9(15.8)$ & - & - & - & - & - \\
\hline $21^{b}$ & 303.5 (11.0) & - & - & - & - & - \\
\hline 22 & $256.6(9.3)$ & + & - & + & - & - \\
\hline 23 & $206.9(7.5)$ & + & - & - & - & - \\
\hline 24 & $179.3(6.5)$ & + & - & - & + & - \\
\hline
\end{tabular}

${ }^{a}$ Asymptomatic patients with maximum cortisol response after ITT test $<20 \mu \mathrm{g} / \mathrm{dll}$.

${ }^{\mathrm{b}}$ Patients with maximum cortisol response after ITT test $>20 \mu \mathrm{g} / \mathrm{dl}$.

${ }^{c}$ Patients with adrenal insufficiency. Patients 4, 5, 8, 19, 20, 22, 23 and 24 had no ITT. 


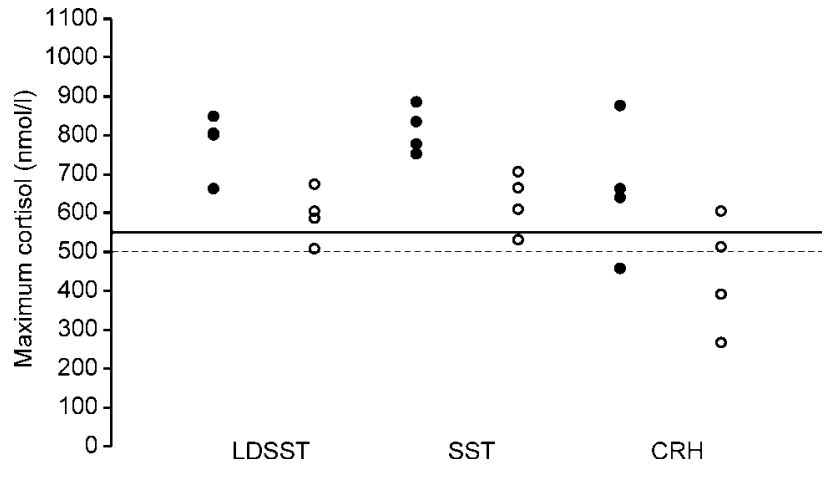

Figure 2 Maximum cortisol responses after LDSST, SST and $\mathrm{CRH}$ test in eight patients in whom ITT was contraindicated. Patients with two clinical manifestations of adrenal insufficiency (cases 5, 8, 22 and 24 (०)) and the others (cases 4, 19, 20 and 23 $(\bullet))$.

response to ITT has been validated against the response to surgical stress and is considered the reference test to evaluate the integrity of the HPA $(6-8)$. Reportedly (6-8), a cortisol response to ITT of $500-550 \mathrm{nmol} / \mathrm{l}(18-20 \mu \mathrm{g} / \mathrm{dl})$ reflects normal functioning of the axis. However, the ITT is contraindicated in infants, and in patients with cardiovascular disease or a history of seizures. For this reason various authors have proposed alternatives to the ITT, including SST, LDSST and CRH tests.

Among the subjects in this study who underwent ITT, the test identified as adrenal insufficient four patients with typical clinical symptoms. The diagnosis was confirmed in all four patients by both LDSST and the $\mathrm{CRH}$ test, while the cortisol response to SST was normal in one. These patients also had subnormal baseline morning cortisol concentrations, although all available data indicate that a low morning cortisol concentration alone is not a reliable predictor of overt adrenal insufficiency $(24,25)$. A subnormal cortisol response to ITT was also found in seven asymptomatic patients, which was not confirmed by SST. The diagnosis was also not confirmed in one and five patients, respectively, by LDSST and CRH. Therefore, in this subset of patients, the response to $\mathrm{CRH}$ correctly identified all but two patients with adrenal insufficiency, while both LDSST and SST were far less accurate. In other words, the LDSST and the SST yielded normal responses in patients with subtle dysfunctions of the HPA detected by ITT. All eight patients in whom ITT was contraindicated were apparently asymptomatic. One of them had a subnormal cortisol response to SST, LDSST and CRH, while three other patients showed discordant responses to the three tests. Based on the results of the group of patients who underwent ITT, subtle adrenal insufficiency could not be excluded in these subjects.

Our results contrast with those reported by other investigators. Weintrob et al. (12) found that in patients with idiopathic multiple pituitary hormone deficits, both SST and LDSST were equivalent to ITT in detecting HPA insufficiency. One of the possible explanations for these contrasting findings may be the fact that in their study all patients may have had clinical adrenal insufficiency, as indicated by their low baseline cortisol concentrations $(80 \pm 24 \mathrm{nmol} / \mathrm{l})$, close to the values of our four patients with overt adrenal insufficiency. Abdu et al. (16) reported that at cortisol cutoff levels of 500 or $600 \mathrm{nmol} / \mathrm{l}$, all patients who failed the ITT also failed the LDSST. They suggested that at a cortisol cut-off of $600 \mathrm{nmol} / \mathrm{l}$ the LDSST is $100 \%$ sensitive without any falsely reassuring results. Other authors have reported a good correlation between the cortisol response to ITT and to $\operatorname{LDSST}(14,15,18)$ or SST. However, most of these studies have been performed in adult subjects. In a study involving thirtytwo patients aged 2-19 years with clinical symptoms suggestive of adrenal insufficiency, Agwu et al. (15) found that the LDSST revealed a mild degree of adrenal insufficiency not detected by the SST; similar findings have been reported in another study by Gonc et al. (23). In their studies, however, none of the patients were tested with the ITT. Ambrosi et al. (14) suggested that LDSST is a useful tool for the initial assessment of HPA function in patients with hypothalamic-pituitary disease. However, a 100\% concordance with the ITT was found only at a cut-off of $750 \mathrm{nmol} / \mathrm{l}$, whereas using a cut-off of $500 \mathrm{nmol} / \mathrm{l}$, the results of ITT and LDSST were concordant in $88 \%$ of patients. Thus, it seems that the cortisol response to LDSST consistently correlates with that of the ITT only when the patients have overt adrenal insufficiency, or at cut-off values higher than 500-550 nmol/l. On the other hand, it must be kept in mind that in occasional cases even the ITT may fail to identify patients with clinically evident cortisol deficiency $(16,26)$.

Although the results of $\mathrm{CRH}$ testing have been reported to correlate with those of ITT in patients with glucocorticoid-induced corticotropin deficiency $(18,20,27)$, the $\mathrm{CRH}$ test has not generally been regarded as a useful tool in the clinical setting (20, 27). Moreover, the variability of cortisol response to $\mathrm{CRH}$ has been possibly attributed to compounding factors, such as preceding corticosteroid therapy or concomitant desmopressin treatment (28). In our study, the cortisol response to $\mathrm{CRH}$ was not always correlated with that of the ITT, with the exception of the four patients with overt adrenal insufficiency. Similar to previous findings, in our normal subjects the cortisol response to $\mathrm{CRH}$ was highly variable. Thus, the lowest cortisol value was chosen as the limit for normal response. Even with these limitations, it provided better results than the SSL and LDSST and it may be considered useful in patients in whom ITT is contraindicated. It must also be pointed out that while the cost of SST, LDSST and ITT is on average comparable to that of routine tests in an endocrine 
setting, the CRH test is still burdened by the cost of the peptide.

In conclusion, none of the tests employed in this study can be considered completely reliable for establishing or excluding the presence of secondary or tertiary adrenal insufficiency, although ITT seems to be the most sensitive for detecting sub clinical or partial ACTH deficiency. Based on the above considerations, our patients in whom ITT was contraindicated cannot be safely considered to have an intact HPA. Therefore, we suggest that patients with isolated GHD or combined pituitary hormone deficiency who are at risk of developing adrenal insufficiency but who cannot undergo ITT be carefully monitored clinically and biochemically. MRI might be of help in identifying those patients with GHD at higher risk of developing other pituitary hormone deficits. In fact, patients with nonidentified pituitary stalks have been found to bear a risk of developing associated hormonal deficits 27 times greater than those with an identified pituitary stalk (21). Our study points out that patients with structural hypothalamic-pituitary abnormalities may develop subtle to complete ACTH deficiency and that these patients should be alerted of the potential risk of acute adrenal insufficiency in cases of stressful events.

\section{References}

1 August GP, Lippe BM, Blethen SL, Rosenfeld RG, Seelig SA, Johanson AJ, Compton PG, Frane JW, Mcclellan BH \& Sherman BM. Growth hormone treatment in the United States: demographic and diagnostic features of 2331 children. Journal of Pediatrics 1990116 899-903.

2 Rona RJ \& Tanner JM. Aetiology of idiopathic growth hormone deficiency in England and Wales. Archives of Disease in Childhood 197752 197-208.

3 Maghnie M, Triulzi F, Larizza D, Preti P, Priora C, Scotti G \& Severi F. Hypothalamic-pituitary dysfunction in growth hormone-deficient patients with pituitary abnormalities. Journal of Clinical Endocrinology and Metabolism 199173 79-83.

4 Lange M, Feldt-Rasmussen U, Svendsen OL, Kastrup KW, Juul A \& Muller J. High risk of adrenal insufficiency in adults previously treated for idiopathic childhood onset growth hormone deficiency. Journal of Clinical Endocrinology and Metabolism $2003 \mathbf{8 8}$ $5784-5789$

5 Walvoord EC, Rosenman MB \& Eugster EA. Prevalence of adrenocorticotropin deficiency in children with idiopathic growth hormone deficiency. Journal of Clinical Endocrinology and Metabolism $2004895030-5034$.

6 Nieman LK. Dynamic evaluation of adrenal hypofunction. Journal of Endocrinological Investigation 200326 74-82.

7 Grinspoon SK \& Biller BM. Clinical review 62: Laboratory assessment of adrenal insufficiency. Journal of Clinical Endocrinology and Metabolism 199479 923-931.

8 Erturk E, Jaffe CA \& Barkan AL. Evaluation of the integrity of the hypothalamic-pituitary-adrenal axis by insulin hypoglycemia test. Journal of Clinical Endocrinology and Metabolism $1998 \mathbf{8 3}$ 2350-2354.

9 Maghnie M, Strigazzi C, Tinelli C, Autelli M, Cisternino M, Loche S \& Severi F. Growth hormone (GH) deficiency (GHD) of childhood onset: reassessment of GH status and evaluation of the predictive criteria for permanent GHD in young adults. Journal of Clinical Endocrinology and Metabolism 199984 1324-1328.
10 Shah A, Stanhope R \& Matthew D. Hazards of pharmacological tests of growth hormone secretion in childhood. British Medical Journal 1992304 173-174.

11 Gleeson HK, Walker BR, Seckl JR \& Padfield PL. Ten years on: Safety of short synacthen tests in assessing adrenocorticotropin deficiency in clinical practice. Journal of Clinical Endocrinology and Metabolism $2003 \mathbf{8 8} 2106-2111$.

12 Weintrob N, Sprecher E, Josefsberg Z, Weininger C, Aurbach-Klipper Y, Lazard D, Karp M \& Pertzelan A. Standard and low-dose short adrenocorticotropin test compared with insulin-induced hypoglycemia for assessment of the hypothalamicpituitary-adrenal axis in children with idiopathic multiple pituitary hormone deficiencies. Journal of Clinical Endocrinology and Metabolism $1998 \mathbf{8 3} 88-92$.

13 Rasmuson S, Olsson T \& Hagg E. A low dose ACTH test to assess the function of the hypothalamic-pituitary-adrenal axis. Clinical Endocrinology (Oxf) 199644 151-156.

14 Ambrosi B, Barbetta L, Re T, Passini E \& Faglia G. The one microgram adrenocorticotropin test in the assessment of hypothalamic-pituitary-adrenal function. European Journal of Endocrinology 1998139 575-579.

15 Agwu JC, Spoudeas H, Hindmarsh PC, Pringle PJ \& Brook CG. Tests of adrenal insufficiency. Archives of Disease in Childhood $199980330-333$.

16 Abdu TA, Elhadd TA, Neary R \& Clayton RN. Comparison of the low dose short synacthen test $(1$ microg), the conventional dose short synacthen test $(250 \mathrm{microg})$, and the insulin tolerance test for assessment of the hypothalamo-pituitary-adrenal axis in patients with pituitary disease. Journal of Clinical Endocrinology and Metabolism $1999 \mathbf{8 4} 838-843$.

17 Mayenknecht J, Diederich S, Bahr V, Plockinger U \& Oelkers W. Comparison of low and high dose corticotropin stimulation tests in patients with pituitary disease. Journal of Clinical Endocrinology and Metabolism $1998 \mathbf{8 3} 1558-1562$.

18 Schlaghecke R, Kornely E, Santen RT \& Ridderskamp P. The effect of long-term glucocorticoid therapy on pituitary-adrenal responses to exogenous corticotropin-releasing hormone. New England Journal of Medicine 1992326 226-230.

19 Schulte HM, Chrousos GP, Avgerinos P, Oldfield EH, Gold PW, Cutler GB Jr \& Loriaux DL. The corticotropin-releasing hormone stimulation test: a possible aid in the evaluation of patients with adrenal insufficiency. Journal of Clinical Endocrinology and Metabolism $1984 \mathbf{5 8} 1064-1067$.

20 Schmidt IL, Lahner H, Mann K \& Petersenn S. Diagnosis of adrenal insufficiency: evaluation of the corticotropin-releasing hormone test and basal serum cortisol in comparison to the insulin tolerance test in patients with hypothalamic-pituitary-adrenal disease. Journal of Clinical Endocrinology and Metabolism $2003 \mathbf{8 8}$ 4193-4198.

21 Maghnie M, Genovese E, Villa A, Spagnolo L, Campan R \& Severi F. Dynamic MRI in the congenital agenesis of the neural pituitary stalk syndrome: the role of the vascular pituitary stalk in predicting residual anterior pituitary function. Clinical Endocrinology (Oxf) $199645281-290$.

22 Maghnie M, Cosi G, Genovese E, Manca-Bitti ML, Cohen A, Zecca S, Tinelli C, Gallucci M, Bernasconi S, Boscherini B, Severi F \& Arico M. Central diabetes insipidus in children and young adults. New England Journal of Medicine $2000 \mathbf{3 4 3}$ 998-1007.

23 Gonc EN, Kandemir N \& Kinik ST. Significance of low-dose and standard-dose ACTH tests compared with overnight metyrapone test in the diagnosis of adrenal insufficiency in childhood. Hormone Research 200360 191-197.

24 Grinspoon SK \& Biller BMK. Laboratory assessment of adrenal insufficiency. Journal of Clinical Endocrinology and Metabolism $199479923-931$.

25 Erturk E, Jaffe CA \& Barman AL. Evaluation of the integrity of the hypothalamic-pituitary-adrenal axis by insulin hypoglycemia test. Journal of Clinical Endocrinology and Metabolism $1998 \mathbf{8 3}$ $2350-2354$. 
26 Tsatsoulis A, Shalet SM, Harrison J, Ratcliffe WA, Beardwell CG \& Robinson EL. Adrenocorticotrophin(ACTH) deficiency undetected by standard dynamic tests of the hypothalamic-pituitary-adrenal axis. Clinical Endocrinology (Oxf) 198828 225-232.

27 Orth DN. Corticotropin-releasing hormone in humans. Endocrine Reviews $199213164-191$.

28 Fujisawa I, Igarashi Y \& Ogawa E. A comparison of pituitary-adrenal responses to corticotropin-releasing hormone, hypoglycaemia and metyrapone in children with brain tumours and growth hormone deficiency. European Journal of Pediatrics $1995 \mathbf{1 5 4}$ $717-722$.

Received 9 December 2004

Accepted 11 February 2005 